\title{
Competências de cálculo mental e iniciação algébrica: algumas relações
}

Mental calculation skills and algebraic initiation: some relationships

\author{
Célia Maria Carolino Pires ${ }^{1}$ \\ Thereza Maria de Fátima Quilici Figueiredo ${ }^{1}$
}

\section{Resumo}

O presente artigo tem como objetivo identificar, compreender e caracterizar conhecimentos prévios de alunos de $6^{\circ}$ e $7^{\circ}$ anos em relação ao cálculo mental e como esses conhecimentos articulam-se com a construção de tarefas que o iniciam no campo da álgebra. Trata-se de uma pesquisa qualitativa realizada com 13 estudantes, sendo sete alunos de uma turma de $6^{\circ}$ ano e seis alunos de outra turma de $7^{\circ}$ ano, todos de uma escola particular da cidade de São Paulo. A primeira atividade proposta pretendia investigar os procedimentos de cálculo mental envolvendo tanto números naturais como números racionais na forma decimal. A segunda atividade tinha a intenção de levantar os procedimentos utilizados para realizar algumas tarefas que caracterizam suas primeiras aproximações com cálculos usando letras. Ao término das análises, observamos que a competência revelada pelos alunos relativa ao cálculo mental com números naturais contribuiu de forma positiva para a exploração das situações algébricas apresentadas, o que mostra a importância de usar esses conhecimentos como âncoras. Os alunos foram capazes de resolver problemas algébricos utilizando seus conhecimentos aritméticos, sem uso formal de manipulações algébricas. Pudemos perceber também que essa mesma competência não se verifica para cálculos com números racionais na forma decimal.

Palavras-chave: conhecimentos prévios; cálculo mental; iniciação algébrica; Educação Matemática.

\section{Abstract}

This article identifies, understands and characterized previous knowledge of students from 6th and 7th grades in relation to mental calculation skills and how these are linked to the construction of tasks that start they in the field of algebra. This is a qualitative study conducted with 13 students, seven students in a class of 6th grade six students from another class of 7th, all in a private school in the city of São Paulo. The first proposed activity intended to investigate the mental calculation procedures involving both natural numbers as rational numbers in decimal form. The second activity was intended to raise the procedures used to perform some tasks that characterize his early approaches to calculations using letters. At the end of the analysis, we found that the competence shown by students on the mental arithmetic with natural numbers contributed positively for the exploitation of algebraic situations presented, which shows the importance of using this knowledge as anchors. Students were able to solve algebraic problems using their knowledge arithmetic without using formal algebraic manipulations. We also realize that such a power not seen for calculations with rational numbers in decimal form.

Keywords: previous knowledge, mental arithmetic, algebraic initiation; Mathematics Education.

\footnotetext{
${ }^{1}$ Pontifícia Universidade Católica de São Paulo - PUC/SP | ccarolinopires@gmail.com
} 


\section{Introdução}

Nossa pesquisa teve motivações iniciais originadas em reflexões, questionamentos e preocupações com nossos alunos de $6^{\circ}$ e $7^{\circ}$ anos que mostravam dificuldades com atividades relacionadas à álgebra. Era forte a sensação de que o contato com a álgebra nessa etapa escolar, que se faz de modo mais formal, constituía um momento crucial na trajetória de aprendizagem dos alunos, e que nem sempre esse momento é tranquilo. Percebíamos que, frequentemente, esses estudantes tinham pouco domínio do cálculo mental. Mas faltavam-nos elementos que justificassem, ou pelo menos ajudassem a explicar, o motivo de tal inquietação.

Foi então que propusemo-nos a estudar possíveis articulações entre procedimentos de cálculo mental e o desempenho em atividades que envolvem a educação algébrica de alunos de $6^{\circ}$ e $7^{\circ}$ anos do Ensino Fundamental. Realizamos uma pesquisa qualitativa com 13 alunos de 11 a 13 anos de idade, todos estudantes de uma mesma escola particular da cidade de São Paulo. O objetivo da nossa pesquisa foi identificar, compreender e caracterizar conhecimentos prévios desses alunos em relação ao cálculo mental e como esses conhecimentos articulam-se com a construção de tarefas que costumam ser apresentadas com o intuito de inseri-lo no campo da Álgebra. As questões de pesquisa foram três: 1) Que procedimentos de cálculo mental são utilizados por esses dois grupos de alunos - um de $6^{\circ}$ e outro de $7^{\circ}$ ano - tanto para cálculos envolvendo números naturais como para cálculos envolvendo números racionais na forma decimal? 2) Que procedimentos são utilizados por esses dois grupos de alunos para realizar algumas tarefas, geralmente apresentadas a alunos de $7^{\circ}$ ano, que caracterizam suas primeiras aproximações com cálculos usando letras? E finalmente, 3) Que relações podem ser observadas no desempenho de alunos, contrapondo-se tarefas aritméticas e tarefas algébricas realizadas por eles?

\section{Apontamentos teóricos}

A concepção construtivista de ensino-aprendizagem defende que as mentes de nossos alunos não são lousas limpas, em branco, na qual podemos escrever o que queremos que eles aprendam. Ela assume que aprender qualquer conteúdo escolar depende do sentido que lhe é atribuído, das conexões que o aluno é capaz de fazer do conceito novo com o conceito que ele já sabe. São os chamados conhecimentos prévios.

Os conhecimentos prévios dos alunos podem abranger tanto informações a respeito do próprio conteúdo novo como conhecimentos que, de maneira direta ou indiretamente, estão relacionados com ele. No contato inicial com o novo conteúdo, esses conhecimentos prévios são fundamentais na construção dos novos conhecimentos. Quanto mais relações com sentido um aluno for capaz de estabelecer entre o que ele já conhece e o novo, mais significativa será a sua aprendizagem.

Para Ausubel (apud MOREIRA, 1982), aprendizagem significativa é um processo pelo qual uma nova informação se relaciona com um aspecto relevante da estrutura do conhecimento do indivíduo. Ou seja, a informação interage com uma estrutura de conhecimento específica, a qual Ausubel chama de conceitos subsunçores (ou esteios), âncoras. 
Se eu tivesse que reduzir toda a psicologia educacional a um único princípio, diria isto: O fator isolado mais importante que influencia a aprendizagem é aquilo que o aprendiz já conhece. Descubra o que ele sabe e baseie nisso os seus ensinamentos. (AUSUBEL, 1980)

Segundo o mesmo autor, o armazenamento das informações no cérebro se processa de maneira organizada e hierárquica, na qual os elementos específicos são ligados a conceitos mais gerais. A estrutura cognitiva passa a ser, portanto, uma estrutura hierárquica de conceitos que são abstrações da experiência do indivíduo. Entretanto, esse processo de ancoragem do novo conceito resulta em crescimento e modificação do conceito subsunçor.

Podemos afirmar, então, que a aprendizagem significativa envolve uma interação entre novas informações e ideias preexistentes na estrutura cognitiva. No caso de nosso estudo, nossa intenção era a de buscar compreender as interações entre as primeiras abordagens de escritas algébricas com as competências aritméticas preexistentes referentes aos cálculos com as operações fundamentais, particularmente com uso de cálculo mental.

Sobre o cálculo mental, o trabalho dessa modalidade de cálculo na escola vem sendo discutido em diferentes documentos curriculares recentes e em alguns artigos publicados a respeito do tema. As propostas mostram a importância do trabalho com diferentes estratégias de cálculos como o mental, com papel e lápis e com uso da calculadora, assim como a relevância em se trabalhar com estimativas e arredondamentos, além dos cálculos exatos.

Tratando-se especificamente do cálculo mental, compreende ressaltar que por ele entendemos:

O conjunto de procedimentos em que, uma vez analisados os dados a serem tratados, estes se articulam, sem recorrer a um algoritmo preestabelecido para obter resultados exatos ou aproximados. Os procedimentos de cálculo mental se apoiam nas propriedades de numeração decimal e nas propriedades das operações, e colocam em ação diferentes tipos de escrita numérica, assim como diferentes relações entre os números (PARRA, 1996, p. 189).

Numa abordagem histórica, recordamos que um dos pilares da escola tradicional constituía-se no domínio das quatro operações básicas. Os cálculos numéricos eram memorizados após uma longa sequência de exercícios. Com o desenvolvimento de novas ideias pedagógicas, a memorização começa a perder valor frente à compreensão. E a escola deixa de ser unicamente transmissora de saberes para se tornar um local de questionamentos e um ambiente de busca pelo conhecimento. Nesse contexto, muitos pesquisadores têm se interessado por conhecer os procedimentos de cálculos utilizados pelos alunos no período escolar.

Um aporte no terreno do cálculo que vamos destacar são as duas categorias de procedimentos consideradas por Groen e Parkman (apud PARRA, 1996, p. 191): os métodos reprodutivo e reconstrutivo. Quando um aluno recupera um resultado de uma operação diretamente de sua memória de longo prazo trata-se, então, do método reprodutivo. Ao passo que, no método reconstrutivo, o aluno chega ao resultado da operação por meio de cálculos. Segundo Fayol (1985, apud PARRA, 1996, p. 191), crianças menores apoiam-se na contagem, em alguns casos de um em um, enquanto adultos recorrem à memória de longo prazo. Ashcraft e Fierman (1982, apud PARRA, 1996, p. 192) estudaram o período de transição do método reconstrutivo para o método reprodutivo e descobriram que ele pode se estender até o fim do Ensino Fundamental.

Tais constatações têm levantado o problema da organização das informações numéricas na memória. Pesquisas realizadas a respeito do assunto são determinantes para 
que possamos fazer considerações na prática educativa. Fisher (1987, apud PARRA, 1996, p. 193) diz que:

\begin{abstract}
somente uma automaticidade - ou, no mínimo, um processo reprodutivo mais que um processo reconstrutivo - ao evocar fatos numéricos, conduzirá os alunos a estimar a ordem das grandezas e visualizar certos erros obtidos com calculadoras ou computadores, quer dizer, a exercer um controle mínimo. Uma ativação automática é muito econômica na medida em que não somente é rápida, mas também não consciente, sem esforço, e não interfere na atividade mental em curso.
\end{abstract}

Neste sentido, surgem reflexões a respeito do papel da escola nessas aprendizagens. Fisher (1987, apud PARRA, 1996, p. 193) formula que é por meio de um trabalho regular e sistemático que os alunos alcançarão o domínio requerido. Cálculos não intencionais e não controlados não são suficientes para o desenvolvimento de um processo reprodutivo. Sem a ação sistemática da escola não é possível para os alunos adquirir e estruturar adequadamente as áreas do conhecimento. E o mesmo acontece, em particular, com o cálculo mental e o seu papel na construção dos conhecimentos matemáticos, aspecto relevante em nossa pesquisa, acerca do qual voltamos a discorrer.

Parra (1996, pp. 195-200) elenca quatro hipóteses didáticas para o ensino do cálculo mental na escola primária: 1) as aprendizagens no terreno do cálculo mental influenciam a capacidade de resolver problemas; 2) o cálculo mental aumenta o conhecimento no campo numérico; 3) o trabalho de cálculo mental habilita para uma maneira de construção do conhecimento que favorece uma melhor relação do aluno com a matemática; e 4) o cálculo mental é uma via de acesso para a compreensão e construção dos algoritmos.

Os currículos atuais de vários países já fazem menção ao cálculo mental e à sua importância. No Brasil, por exemplo, os Parâmetros Curriculares Nacionais (PCN) para o Ensino Fundamental, sugerem que sejam ampliados os procedimentos de cálculo mental pelo reconhecimento das regularidades e pela antecipação e verificação de resultados. À medida que o aluno avança nas séries e possui uma visão mais ampla do sistema de numeração decimal, ele pode aumentar seu repertório até que seja suficiente para transferir e utilizar seus procedimentos de cálculo mental com os números racionais.

\title{
Sobre a introdução algébrica nos anos finais do Ensino Fundamental
}

Passamos, agora, a discorrer um pouco acerca da álgebra nos nossos documentos curriculares.

Na análise dos PCN de $1^{a}$ a $4^{a}$ séries (1997), encontramos menção à álgebra quando, na seleção de conteúdos, o documento ressalva a necessidade de interligar os campos da aritmética, da álgebra e da geometria. Comenta, ainda, que:

embora nas séries iniciais já se possa desenvolver uma pré-álgebra, é especialmente nas séries finais do ensino fundamental que os trabalhos algébricos serão ampliados; trabalhando com situações-problema, o aluno reconhecerá diferentes funções da álgebra (como modelizar, resolver problemas aritmeticamente insolúveis, demonstrar), representando problemas por meio de equações (identificando parâmetros, variáveis e relações e tomando contato com fórmulas, equações, variáveis e incógnitas) e conhecendo a "sintaxe" (regras para resolução) de uma equação (p. 39). 
É, porém, nos PCN de $5^{a}$ a $8^{a}$ séries (1998) que encontramos maiores especificações e orientações em relação ao ensino da álgebra que, apesar de poder já se desenvolver desde as séries iniciais, é ampliada nas séries finais do Ensino Fundamental. Nessas orientações curriculares, fica claro que o estudo da álgebra constitui um espaço bastante significativo para que o aluno desenvolva e exercite sua capacidade de abstração e generalização, além de Ihe possibilitar a aquisição de uma poderosa ferramenta para resolver problemas. Conforme o documento em questão, algumas das diferentes funções da álgebra são: generalizar padrões aritméticos, estabelecer relação entre duas grandezas, modelizar e resolver problemas aritmeticamente difíceis. Além de possibilitar a resolução de problemas por meio de equações e inequações, diferenciando parâmetros, variáveis, incógnitas e tomando contato com fórmulas. Esse direcionamento dado à álgebra, a partir da generalização de padrões, bem como o estudo da variação de grandezas, possibilita a exploração da noção de função, cuja abordagem formal será feita nos anos seguintes, no Ensino Médio.

Os mesmos PCN alertam o professor para a importância de não abandonar a aritmética frente ao uso da álgebra.

É importante salientar que no quarto ciclo não se pode configurar o abandono da Aritmética, como muitas vezes ocorre. Os problemas aritméticos praticamente não são postos como desafios aos alunos deste ciclo; em geral, as situações trabalhadas pelos professores privilegiam a aplicação de conceitos algébricos. Pode-se ate afirmar que os procedimentos "não-algébricos" (os que não utilizam equações, sistemas etc.) para resolver problemas são desestimulados nos últimos anos do ensino fundamental, mesmo em situações em que a álgebra não e necessária ( $P C N$ de $5^{a}$ a $8^{a}$ séries, p. 83).

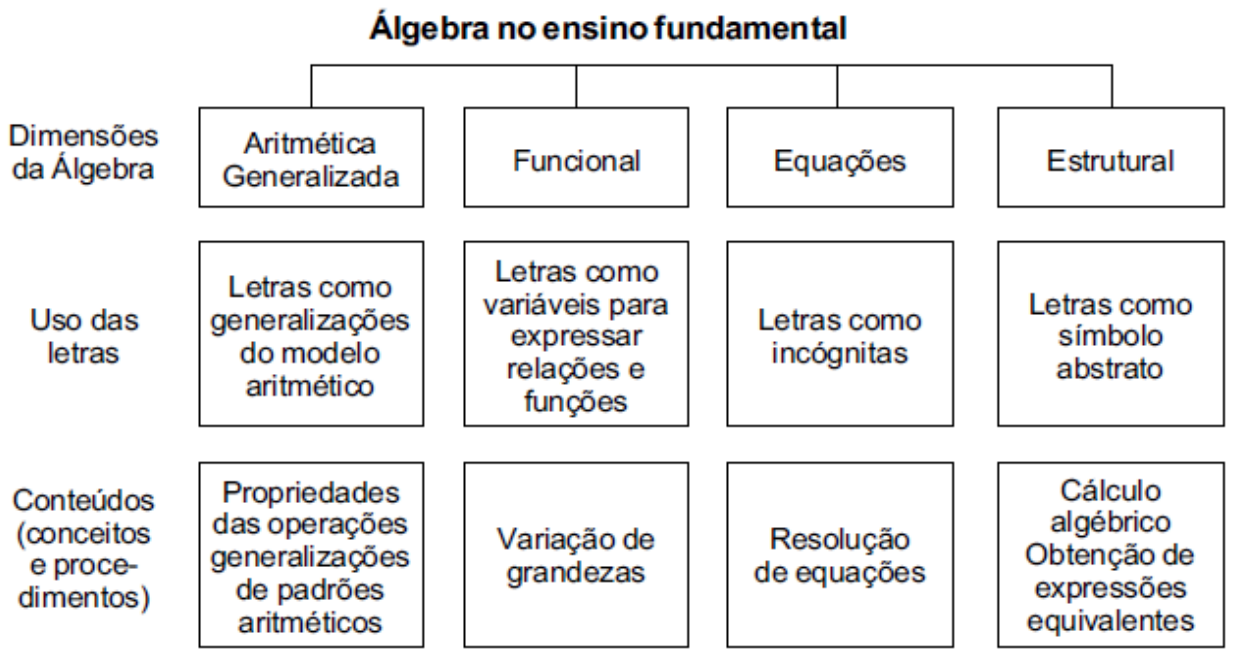

Quadro 1: PCN: $5^{a}$ a $8^{a}$ séries do Ensino Fundamental (Brasil, 1998, p.116)

O Quadro 1 sintetiza de forma bastante simplificada as diferentes interpretações da álgebra escolar e as diferentes funções das letras.

Em nossas leituras e análises, percebemos uma influência das concepções de Usiskin (1995) na elaboração do quadro acima. Por isso, vimos por bem fazer uma pausa em nossas considerações a respeito dos PCN e escrever um breve relato acerca desse teórico.

Zalman Usiskin, atual diretor da Universidade de Chicago, professor e pesquisador com vários artigos na área de Educação Matemática, afirma que as diferentes dimensões da álgebra relacionam-se com os diferentes usos das variáveis. Sintetiza sua teoria em quatro diferentes dimensões algébricas, as quais descreveremos a seguir. 
Na primeira dimensão, o autor descreve a álgebra como aritmética generalizada. Neste contexto, é natural pensar as variáveis como generalizadoras de modelos. Em seus exemplos, cita que $3+5 \times 7=5 \times 7+3$ pode ser generalizado como $a+b=b+a$. Dentro dessa ideia, as instruções para o aluno são traduzir e generalizar, técnicas importantes tanto para a álgebra como para a aritmética (USISKIN, 1995, p. 13).

Na segunda dimensão, a álgebra é definida como um estudo de procedimentos para resolver certos tipos de problemas. Em seus exemplos, coloca o seguinte problema: "adicionado 3 ao quíntuplo de um certo número, a soma é 40. Achar o número". A questão pode ser traduzida na linguagem algébrica $5 x+3=40$ (p. 14). Alguns alunos podem ser capazes de resolver esse problema aritmeticamente, subtraindo 3 do número 40 e dividindo o resultado por 5, sem recorrer aos procedimentos formais das resoluções algébricas. Enquanto outros, apesar de dominarem as resoluções formais, podem não ter a compreensão de seus procedimentos, tornados mecânicos. Dentro dessa dimensão, as palavras chaves são simplificar e resolver.

Na terceira dimensão, a álgebra é tratada como estudo de relações entre grandezas. Nesse contexto, uma letra pode depender dos diferentes valores numéricos atribuídos a outra letra. Por exemplo, na sentença $y=3 x+5$, os valores de y estão diretamente relacionados aos possíveis valores atribuídos a $\mathrm{x}$. Podemos falar em argumento (isto é, a letra representa os valores do domínio de uma função) ou em parâmetro (isto é, a letra representa um número do qual dependem outros números).

Por fim, na quarta dimensão, a álgebra é vista como estudo das estruturas como grupos, anéis, domínios de integridade, corpos e espaços vetoriais, todos temas de estudos da álgebra nos cursos superiores. Segundo Usiskin (1995, p. 18), reconhecemos a álgebra como estudo das estruturas também pelas propriedades que atribuímos às operações com números reais e polinômios. Como exemplo, o autor cita o polinômio de 3x2 + 4ax - 132a2 e sua forma fatorada $(3 x+22 a)(x-6 a)$. Para testar a resposta, normalmente se solicita aos alunos que multipliquem os binômios. Nesse procedimento, as letras são tratadas como sinais (símbolos) no papel, sem nenhuma referência numérica. Na dimensão da álgebra como estudo das estruturas, a variável é pouco mais que um símbolo arbitrário.

\section{Metodologia e sujeitos da pesquisa}

Em nossa pesquisa, optamos por obter dados descritivos a partir de um grupo composto por treze alunos, sete de $6^{\circ}$ ano e seis de $7^{\circ}$ ano, estudantes de uma escola particular localizada na zona oeste da capital paulistana. Optamos também por coletar dados por meio de contato direto nosso com esses estudantes. Ao analisar esses dados, vamos colocar atenção nos procedimentos desses alunos, em suas atitudes, questionamentos e produções e não apenas no resultado correto ou incorreto de suas resoluções.

Os encontros com os alunos aconteceram em duas fases. A primeira fase envolveu a aplicação da primeira atividade, cujo objetivo foi identificar quais procedimentos de cálculo mental são utilizados por esses alunos para efetuar cálculos envolvendo números naturais e números racionais na forma decimal. Nessa fase, aconteceram três encontros com cada grupo de alunos, com duração média de uma hora e meia cada. Como tínhamos doze sequências de atividades a serem aplicadas nesses três encontros, foram organizados três momentos com quatro sequências por vez. Cada grupo respondeu às doze sequências de operações sem fazer uso de algoritmo ou calculadora. Era apresentada na lousa uma 
operação de cada vez e o aluno registrava individualmente o resultado numa folha de papel. Durante a realização dos cálculos, não houve comunicação entre os alunos nem interferência externa de ninguém. Foi solicitado que não fosse feito o uso da borracha a fim de que nenhum registro se perdesse. Após o término de cada sequência, pedíamos aos alunos que indicassem oralmente as respostas dadas e que explicassem ao grupo como chegaram aos resultados. Faz-se importante ressaltar que, nesse momento, os depoimentos eram coletivos e todos ouviam as exposições dos colegas. Esses depoimentos foram gravados em áudio.

A segunda fase envolveu a aplicação da segunda atividade, cujo objetivo foi investigar os procedimentos que esses alunos utilizam para realizar tarefas usando letras. Essa atividade foi composta de seis questões, respondidas em papel, individualmente, num encontro de aproximadamente uma hora. As respostas não receberam nenhum tipo de interferência externa e foi solicitado a cada aluno que não usasse borracha e registrasse seu raciocínio da maneira mais clara possível. Após uma análise prévia das produções dos alunos, aconteceu uma conversa com cada um deles a fim de esclarecer algumas formas de pensamento.

\begin{tabular}{|c|c|c|c|c|}
\hline Grupo & Nomes & Idade & Sexo & Aproveitamento \\
\hline \multirow{7}{*}{$\begin{array}{l}\text { Alunos do } \\
60 \text { ano }\end{array}$} & Fabio & 11 & $\mathrm{M}$ & Bom aluno \\
\hline & Elaine & 11 & $\mathrm{~F}$ & Boa aluna \\
\hline & Isabel & 11 & $\mathrm{~F}$ & Aluna mediana \\
\hline & Laura & 11 & $\mathrm{~F}$ & Aluna mediana \\
\hline & Valéria & 11 & $\mathrm{~F}$ & Aluna com dificuldades \\
\hline & Guilherme & 11 & $M$ & Aluno com dificuldades \\
\hline & Paulo & 12 & M & Aluno com dificuldades \\
\hline \multirow{6}{*}{$\begin{array}{l}\text { Alunos do } \\
70 \text { ano }\end{array}$} & Marcela & 12 & $\mathrm{~F}$ & Boa aluna \\
\hline & Patrícia & 12 & $\mathrm{~F}$ & Boa aluna \\
\hline & Giovanna & 12 & $\mathrm{~F}$ & Aluna mediana \\
\hline & Theo & 12 & M & Aluno mediano \\
\hline & Larissa & 12 & $\mathrm{~F}$ & Aluna com dificuldades \\
\hline & Neide & 13 & $\mathrm{~F}$ & $\begin{array}{l}\text { Aluna com dificuldades, } \\
\text { refazendo a série }\end{array}$ \\
\hline
\end{tabular}

Quadro 2: Caracterização dos sujeitos de pesquisa

Os sujeitos participantes da pesquisa receberam nomes fictícios e têm idades entre 11 e 13 anos, Pertencem a ambos os sexos e têm diferentes níveis de desempenho na Matemática. Para descrevê-los, utilizamos três categorias de aproveitamento na disciplina, numa escala de zero a dez: bom aluno, para aqueles que alcançam notas superiores a 8,0; aluno mediano para aqueles cujas notas estão entre 5,0 e 7,5; e aluno com dificuldades para aqueles cujas notas são inferiores a 5,0. Todos os alunos são de uma mesma escola desde pequenos e, embora tenham tido diferentes professores polivalentes nos anos iniciais do Ensino Fundamental, foram todos oriundos de projetos de ensino comuns e de estratégias parecidas de aprendizagem. Analisando o ensino da Matemática desses alunos no $4^{\circ}$ e $5^{\circ}$ anos, percebemos uma preocupação de seus professores em desenvolver estratégias de cálculo mental e utilizá-las de maneira sistemática na resolução de problemas. O quadro a seguir relaciona e descreve os alunos participantes da pesquisa. 
Descrevendo as atividades

A primeira atividade foi composta de doze sequências, que foram aplicadas aos alunos em três encontros. No primeiro encontro, foram trabalhadas as sequências 1 a 4; no segundo encontro, as sequências 5 a 8; e no terceiro encontro, as sequências 9 a 12. Cada sequência foi composta de quinze itens, sendo dez cálculos envolvendo números naturais e cinco cálculos envolvendo números racionais na forma decimal.

Trazemos alguns exemplos de sequências dessa primeira atividade.

\section{Sequência 3}

Objetivo: Efetuar mentalmente cálculos do tipo a $+\mathrm{a}$, envolvendo números naturais e números racionais na forma decimal.

\begin{tabular}{|c|c|c|c|c|}
\hline $5+5$ & $9+9$ & $12+12$ & $15+15$ & $26+26$ \\
\hline $50+50$ & $90+90$ & $120+120$ & $150+150$ & $260+260$ \\
\hline $0,5+0,5$ & $0,9+0,9$ & $0,12+0,12$ & $0,15+0,15$ & $0,26+0,26$ \\
\hline
\end{tabular}

\section{Sequência 4}

\begin{tabular}{|c|c|c|c|c|}
\hline \multicolumn{5}{|c|}{$\begin{array}{l}\text { Objetivo: Efetuar mentalmente cálculos do tipos } a+(a+1) \text { envolvendo } \\
\text { números naturais e números racionais na forma decimal. }\end{array}$} \\
\hline $5+6$ & $9+10$ & $12+13$ & $15+16$ & $26+27$ \\
\hline $50+51$ & $90+91$ & $120+121$ & $150+151$ & $260+261$ \\
\hline $0,5+1,5$ & $0,9+1,9$ & $0,12+1,12$ & $0,15+1,15$ & $0,26+1,26$ \\
\hline
\end{tabular}

A segunda atividade foi composta de seis questões abertas e os estudantes poderiam responder da maneira que julgassem correto. As questões, subdivididas em itens, eram respondidas em folha de papel, individualmente. Segue uma das questões envolvidas.

\section{Questão 4}

Objetivo: Calcular o valor de uma letra numa igualdade, sendo que essa letra se refere a um número específico, porém desconhecido, ou seja, funciona como incógnita.

Responda:

Qual o valor de $\mathrm{x}$ que torna verdadeira a igualdade $2 \mathrm{x}+1=71$ ?

Qual é o número que adicionado à sua metade resulta 54 ?

Duplicando a soma de um número com três obtém-se 14. Que número é esse? 


\begin{tabular}{|l|}
\hline Questão 6 \\
\hline $\begin{array}{l}\text { Objetivo: Identificar a letra numa expressão funcional em situações em que ela é } \\
\text { entendida como variável para expressar relações e funções. }\end{array}$ \\
\hline Responda: \\
Qual o valor de y na expressão $\mathrm{y}=\mathrm{x}+2$ se $\mathrm{x}=12 ?$ \\
Qual o valor de y na expressão $\mathrm{y}=3 \mathrm{x}+2$ se $\mathrm{x}=\frac{1}{3} ?$
\end{tabular}

Analisando as atividades

A análise das atividades foi realizada aluno por aluno, observando cada atividade, identificando acertos e erros e tentando compreender e caracterizar os conhecimentos prévios envolvidos.

A cada aluno, após a análise de suas duas atividades, elaboramos uma síntese do seu desempenho, como o modelo que mostramos na Figura 1. Os espaços preenchidos em verde simbolizam os acertos daquele aluno. Os preenchidos em vermelho, os erros. E questões deixadas em branco estão indicadas na cor azul.

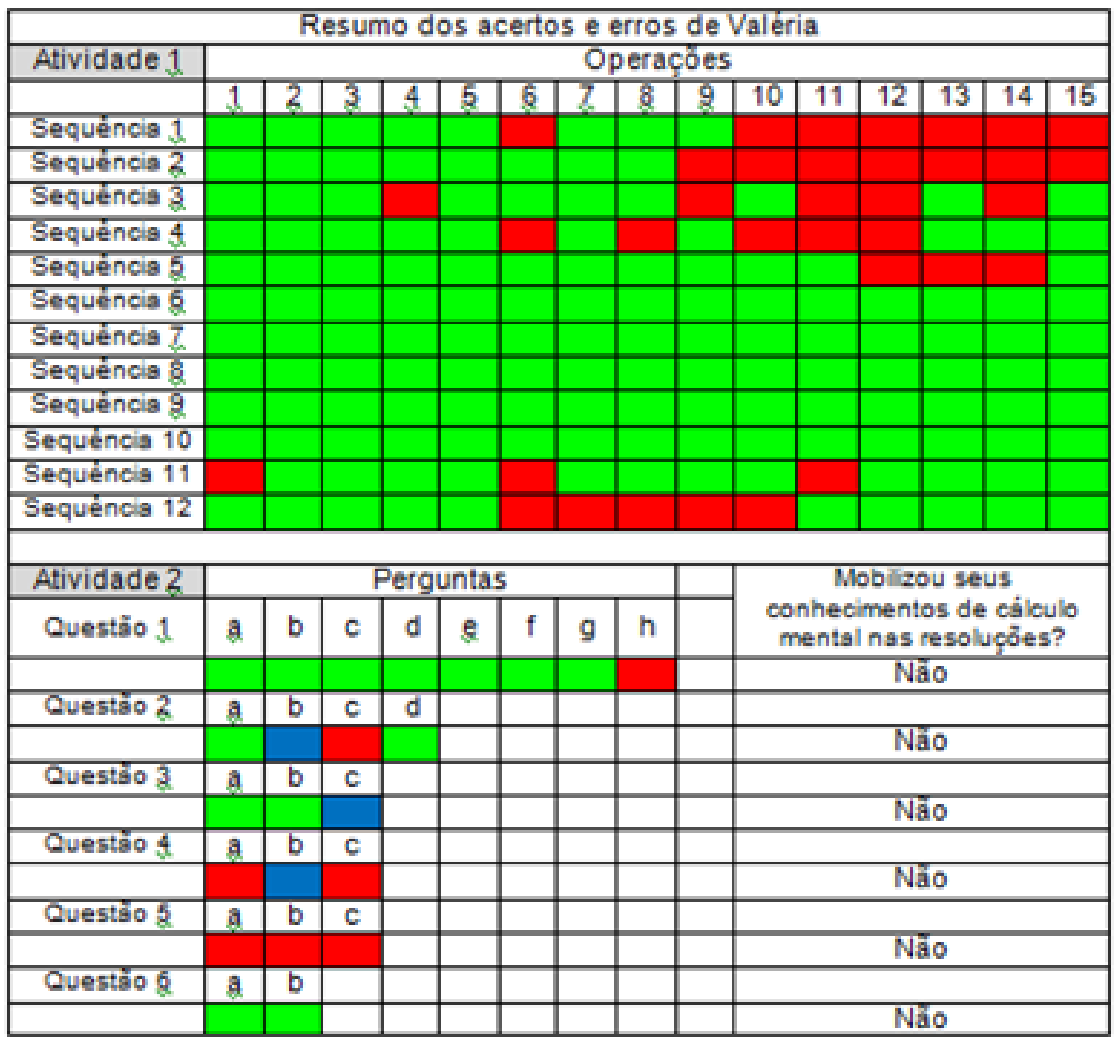

Figura 1: Modelo do resumo da análise

\section{Revelações a partir da Atividade 1}

Com base nas observações dos resultados da primeira atividade e na análise dos comentários feitos pelos alunos, pudemos levantar alguns procedimentos de cálculo mental 
utilizados pelos alunos para cálculos envolvendo números naturais e números racionais na forma decimal.

$1^{\circ}$. Os alunos têm relativa facilidade em adicionar ou subtrair 1 aos números naturais menores. Quando as adições envolvem parcelas de maior grandeza, eles demandam maior tempo para pensar e ainda cometem erros nas operações cujas parcelas terminam por nove. Encontrar o sucessor e o antecessor de números naturais como 99, 999 ou 9999 não é uma tarefa considerada fácil pelos alunos.

\begin{tabular}{|c|c|c|}
\hline Cálculo solicitado & $\begin{array}{c}\text { Sequência 1 } \\
\text { Cálculos do tipo a +1 }\end{array}$ & $\begin{array}{c}\text { Sequência 2 } \\
\text { Cálculos do tipo a - 1 }\end{array}$ \\
\hline $9999+1$ & 100000 & 1,0 \\
\hline $1,1-1$ & & \\
\hline
\end{tabular}

\section{Protocolo de Isabel}

$2^{\circ}$. Alguns alunos apresentaram facilidade na realização de cálculos básicos, como por exemplo, adicionar números iguais, multiplicar por dez ou identificar parcelas cuja adição resulta dez. Esses alunos foram capazes de resolver operações mais complexas utilizando-se desses cálculos como âncoras.

Estratégia descrita por Theo para calcular mentalmente 26 + 26:

"Primeiro somei 20 + 20, que é mais fácil. Depois, fiz 6 + 6. Aí, juntei tudo."

\begin{tabular}{|c|c|c|}
\hline Cálculo solicitado & $\begin{array}{c}\text { Sequência 1 } \\
\text { Cálculos do tipo a + 1 }\end{array}$ & $\begin{array}{c}\text { Sequência 2 } \\
\text { Cálculos do tipo a - 1 }\end{array}$ \\
\hline $1,1+1$ & 1,2 & \\
\hline $3,2+1$ & 3,3 & \\
\hline $24,7+1$ & 24,8 & 4,2 \\
\hline $4,3-1$ & & 14,7 \\
\hline $14,8-1$ & & 238,4 \\
\hline $238,5-1$ & & \\
\hline
\end{tabular}

Protocolo de Valéria

30. Em diversas situações foram comuns os equívocos com as operações envolvendo os números racionais na forma decimal. Os erros cometidos são quase sempre decorrentes da falta de significado atribuído à notação escrita desses números o que os leva a produzir respostas equivocadas.

$4^{\circ}$. Muitos alunos apoiaram-se em diferentes recursos para operar mentalmente: fizeram uso da decomposição dos números; usaram a tabuada do dois para adicionar parcelas iguais; modificaram os valores envolvidos para operar com maior facilidade e fizeram a compensação no final; usaram estratégias de arredondamento e simplificação; associaram números racionais na forma decimal ao sistema monetário para facilitar as contas; e usaram as propriedades associativa e comutativa, mesmo sem tê-las nomeado ou mesmo as identificado.

Ex: Na sequência 4, para efetuar 0,9 + 1,9 mentalmente, muitos alunos ficaram com dúvidas. Marcela, mais tarde, deu a seguinte dica aos colegas: 
"Às vezes é mais fácil arredondar antes de somar. Por exemplo: 0,9 é quase 1 e 1,9 é quase 2. Por isso, para somar 0,9 com 1,9 eu pensei $1+2=3$ e subtrai 0,2 resultando $2,8^{\prime \prime}$.

5․ Alguns alunos mostraram habilidade no cálculo mental. Quando precisaram, porém, operar com números racionais na forma fracionária, abandonaram essa habilidade e utilizaram recursos formais para resolver o exercício, confundindo-se com o procedimento utilizado e errando o exercício. Demonstravam estar fazendo a tarefa mecanicamente, sem compreensão dos procedimentos.

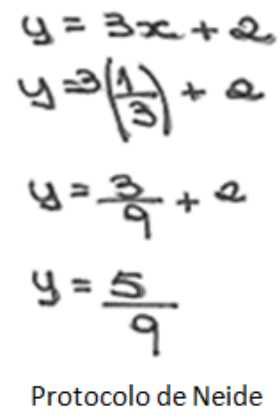

60. Para realizar cálculos sem o uso de papel e lápis, alguns alunos imaginam o algoritmo em suas mentes e realizam os mesmos procedimentos mecânicos que fariam se pudessem "montar a conta".

Comentário de Guilherme:

"Esse tal cálculo mental é muito perigoso. Não dá para confiar. Por isso, é sempre melhor montar a continha na cabeça".

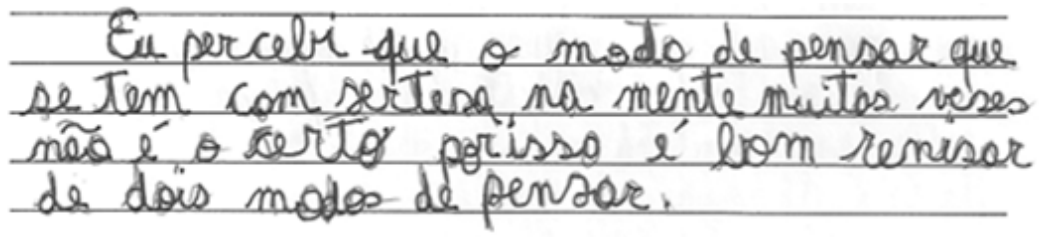

Registro de Guilherme

70. As tabuadas do dois, do cinco e do dez foram consideradas pelos alunos as mais fáceis e todos utilizaram-se do método reprodutivo, no sentido atribuído por Groen e Parkman (apud PARRA, 1996), para resolver essas contas. Os cálculos que envolviam a tabuada do 8 foram descritos como difíceis e mais demorados. Os alunos recorreram ao método reconstrutivo. Poucos estudantes observaram regularidades com as presentes nas tabuadas do dois, do quatro e do oito.

Comentário de Giovanna:

"Não lembrava o resultado de $4 \times 7$. Por isso, primeiro fiz $4 \times 5$ igual a 20. Depois, fui somando de 4 em 4." 


\begin{tabular}{|c|c|}
\hline Cálculo solicitado & $\begin{array}{c}\text { Sequência 12 } \\
\text { Cálculos do tipo a : b }\end{array}$ \\
\hline $1,4: 0,7$ & 0,2 \\
\hline $2,1: 0,7$ & 0,3 \\
\hline $3,5: 0,7$ & 0,5 \\
\hline $4,9: 0,7$ & 0,7 \\
\hline $5,6: 0,7$ & 0,8 \\
\hline
\end{tabular}

Protocolo de Fábio

8. A divisão foi eleita pelos alunos como a operação mais difícil de todas. Principalmente nas situações que envolvem números racionais na representação decimal. Muitos evidenciaram a crença de que divisões com números racionais na forma decimal precisam ter, obrigatoriamente, resultados também racionais na forma decimal.

9०. Na medida em que os alunos comentavam suas resoluções no grupo, os erros foram diminuindo e muitos alunos que antes não sabiam escolher recursos pertinentes para auxiliar os cálculos, ao final do processo já se mostravam mais seguros em suas opções e até conseguiam fundamentar suas decisões. Ficou clara a importância em socializar resultados e reconhecer a utilização de determinados recursos.

\section{Revelações a partir da Atividade 2}

Com base nas observações dos resultados da segunda atividade e na análise dos comentários feitos pelos alunos, pudemos levantar alguns procedimentos que são utilizados por eles para realizar algumas tarefas, geralmente apresentadas a alunos de $7^{\circ}$ ano, e que caracterizam suas primeiras aproximações com cálculos usando letras.

$1^{\circ}$. Os alunos souberam lidar muito bem com as situações de cálculo de "valor numérico". Os alunos de $6^{\circ}$ ano, na sua maioria, utilizaram o algoritmo para mostrar o seu raciocínio e o próprio algoritmo acaba sendo a resposta do exercício. Os alunos de $7^{\circ}$ ano já utilizaram maneiras diferentes de resolução, a maioria substituindo a letra pelo valor numérico na expressão matemática e calculando o resultado. Eles estão mais próximos da linguagem formal das resoluções algébricas. Os modelos abaixo refletem diferentes resoluções apresentadas pelos alunos.
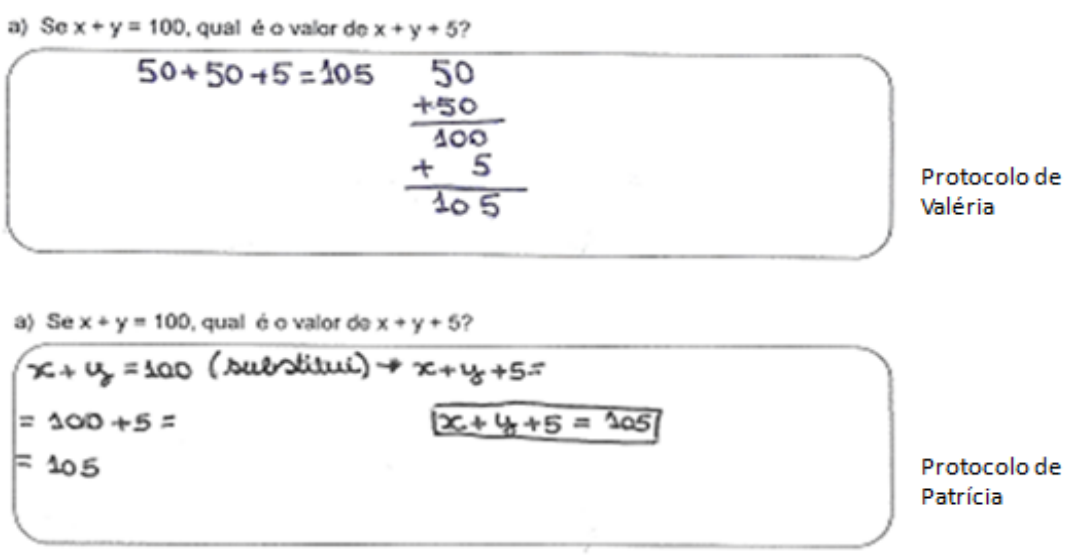
$2^{\circ}$. Em situações em que a letra aparece como variável para expressar relações e funções, os alunos souberam, na sua maioria, reconhecer seu papel e resolveram corretamente os exercícios, cada um a seu modo.

a) Qual o valor de $y$ na expressăo $y=x+2$ se $x=12$ ?

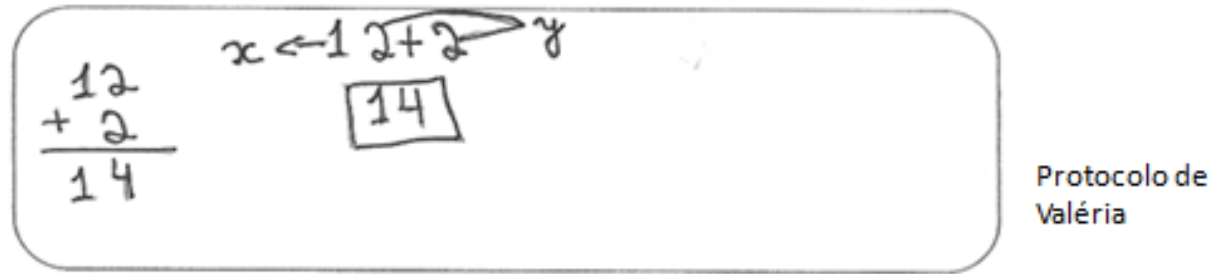

a) Qual o valor de $y$ na expressato $y=x+2$ so $x=12$ ?

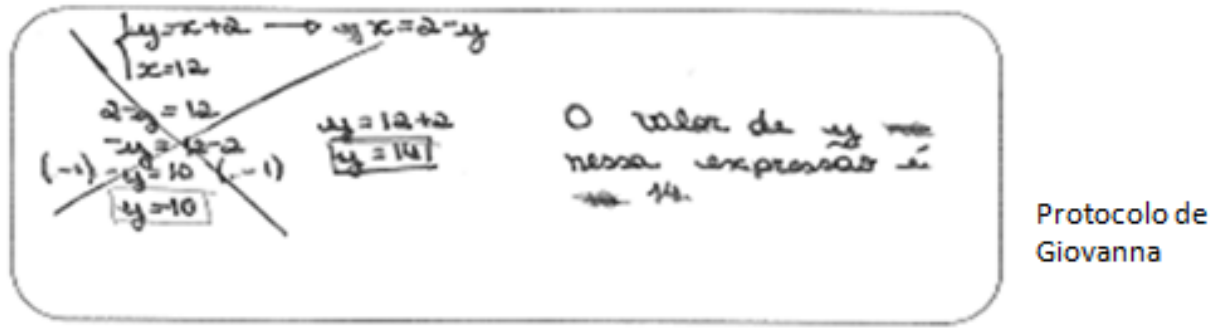

30. Na resolução de equações, ou de problemas que poderiam ser resolvidos com o uso das equações, a maioria dos alunos de $7^{\circ}$ ano preferiu recorrer aos procedimentos formais desse tipo de resolução. Por sua vez, os alunos de $6^{\circ}$ ano, desconhecedores desses procedimentos formais, tiveram que mobilizar seus conhecimentos aritméticos para resolver essas situações. Alguns conseguiram, outros não.

b) Qual ê o número que adicionado à sua motade resulta 54?

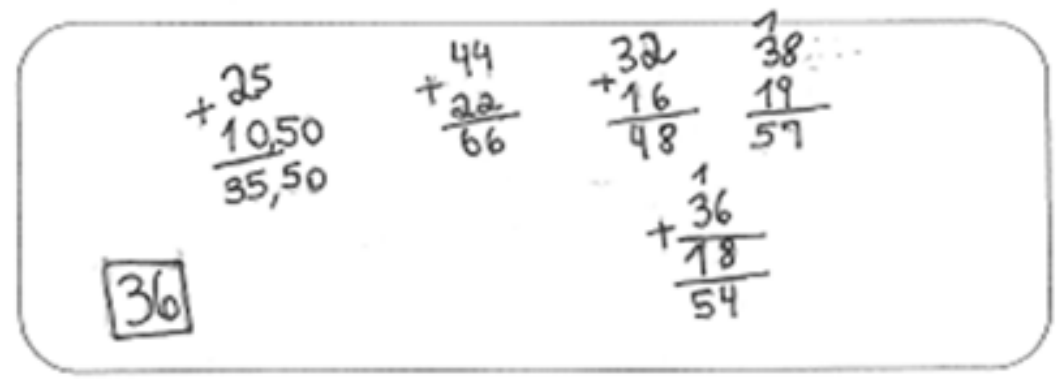

Protocolo de Guilherme

b) Qual bo número que adicionado a sua metade resulta 54?

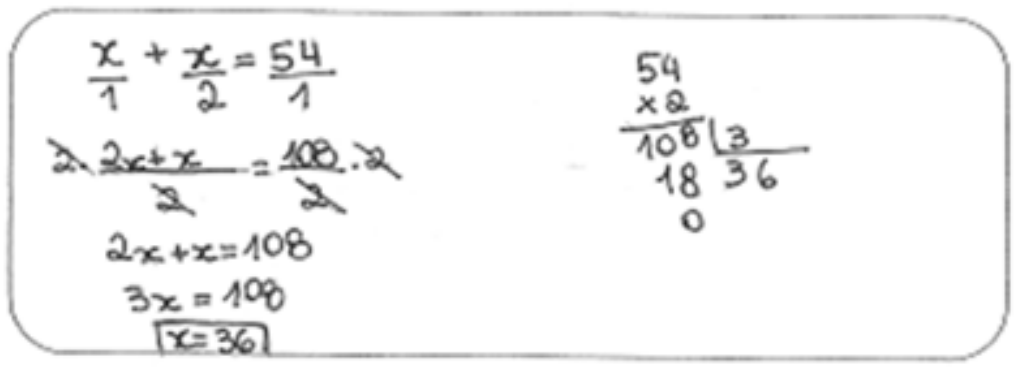

Protocolo de Theo

$4^{\circ}$. Vários alunos utilizaram-se da ideia de operação inversa para resolver problemas que envolveriam equações. 
a) Qual o valor de $x$ que torna verdadeira a igualdade $2 x+1=71$

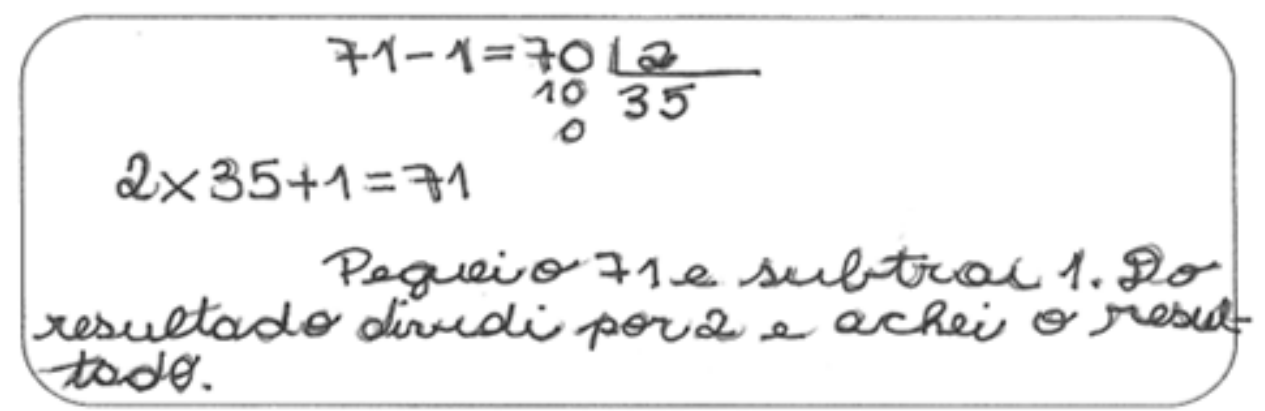

\section{Protocolo de Elaine}

50. A dimensão da álgebra que utiliza as letras como generalizações do modelo aritmético foi aquela que demonstrou maior complexidade de compreensão por parte dos alunos. Muitos fizeram uso de substituições aleatórias para checar resultados. E justificaram a generalização por meio de alguns exemplos.

Assinale as altemativas corretas, considerando n um número natural:

× a expressäo $2 n-1$ designa os nùmeros impares

X a expressão $2 \mathrm{n}$ designa os números pares

c) a expressaio $n+1$ representa os nümeros impares

Protocolo de Marcela

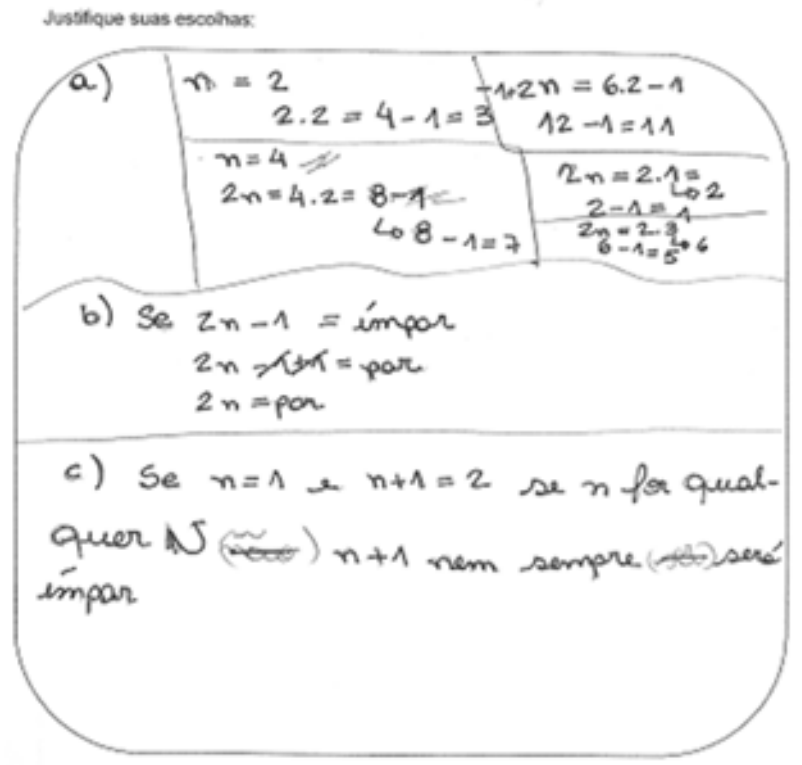

6. A maioria dos alunos fez uso do cálculo mental enquanto resolvia os exercícios com letras. Alguns recorrem ao algoritmo por sentirem maior segurança. Outros, para demonstrar o raciocínio utilizado com clareza. Mas ficou claro que o algoritmo aparecia, na maioria das vezes, em situações que envolviam os números racionais na forma decimal e na forma fracionária. Nesses casos, até mesmo os alunos que utilizavam o cálculo mental com desenvoltura, recorriam ao algoritmo como forma de verificação.

\section{Considerações finais}

Muitos alunos foram capazes de resolver problemas simples sem o uso formal das manipulações algébricas. Por isso, é preciso lembrar que, ao introduzirmos esse formalismo próprio da educação algébrica, a nova ferramenta deve facilitar as resoluções sem anular aquilo que o aluno já sabia. 
É importante salientar que nos anos finais do Ensino Fundamental as situações trabalhadas pelos professores privilegiam a aplicação de conceitos algébricos. E, muitas vezes, os procedimentos que não utilizam equações e sistemas para resolver problemas são desestimulados, mesmo em situações em que uso da álgebra não é obrigatoriamente necessário. É importante que as soluções aritméticas não sejam abandonadas, mas que passem a conviver como as novas ferramentas disponíveis.

Desse modo, é desejável que o professor proponha aos alunos a análise, interpretação, formulação e resolução de novas situações-problema, envolvendo números naturais, inteiros e racionais e os diferentes significados das operações, e que valorize as resoluções aritméticas tanto quanto as algébricas.

\section{Referências}

AUSUBEL, David P.; NOVAK, Joseph D.; HANESIAN, Helen. Psicologia educacional. Rio de Janeiro: Interamericana, 1980.

BRASIL, Secretaria da Educação. Parâmetros Curriculares Nacionais (PCN): Matemática, Ensino de $1^{a} a$ $4^{a}$ série. Brasília: Ministério da Educação, 1997.

BRASIL, Secretaria da Educação. Parâmetros Curriculares Nacionais (PCN): Matemática, Ensino de $5^{a}$ a 8a série. Brasília: Ministério da Educação, 1998.

COLL, Cesar, et al. O construtivismo na sala de aula. São Paulo: Ática, 2009.

FIGUEIREDO, T. M. F. Q. Possíveis relações entre competências de cálculo mental e iniciação algébrica de alunos de $6^{\circ}$ e $7^{\circ}$ anos do ensino fundamental. Dissertação de Mestrado. Pontifícia Universidade Católica de São Paulo: São Paulo, 2013.

MIRAS, Mariana. Um ponto de partida para a aprendizagem de novos conteúdos: os conhecimentos prévios. In: COLL, C. et al. O construtivismo na sala de aula. São Paulo: Ática, 2009.

MOREIRA, Marco Antônio. Teorias de aprendizagem. São Paulo: EPU, 1999.

MASINI, Elcie F. Salzano. Aprendizagem significativa: a teoria de David Ausubel. São Paulo: Centauro, 1982.

PARRA, Cecilia; SAIZ, Irma. et al. Didática da matemática: reflexões psicopedagógicas. Porto Alegre: Artmed, 1996.

SÃO PAULO, Secretaria Municipal de Educação. Orientações Curriculares e proposição de expectativas de aprendizagem para o ensino fundamental: ciclo II: Matemática. São Paulo: Secretaria Municipal de Educação, 2007.

USISKIN, Zalman. Concepções sobre a álgebra da escola média e utilizações das variáveis. In: COXFORD, Arthur F. e SHULTE, Albert P. As ideias da álgebra. São Paulo: Atual, 1995. 